\title{
AWARENESS ABOUT VITAMIN D DEFICIENCY AND ITS RELATION WITH DIFFERENT DISORDERS
}

\author{
Seema Maini ${ }^{1}$, Rajiv Arora², Harleen Kaur ${ }^{3}$
}

1 Professor, Department of Physiology, Punjab Institute of Medical Sciences, Jalandhar, Punjab.

2 Professor and HOD, Department of Physiology, Punjab Institute of Medical Sciences, Jalandhar, Punjab.

${ }^{3}$ Associate Professor, Department of Physiology, Punjab Institute of Medical Sciences, Jalandhar, Punjab.

\section{ABSTRACT}

\section{BACKGROUND}

Vitamin D deficiency is prevalent amongst all age groups all over the world. The purpose of this study was to assess the level of awareness about vitamin D deficiency and its related disorders, so that effective educational programmes can be designed to prevent this deficiency.

\section{MATERIALS AND METHODS}

Data was collected using a questionnaire to assess the level of knowledge about Vitamin D, its sources, its health benefits and complications of its deficiency.

\section{RESULTS}

It was observed that most of the subjects did not know about the sources of vitamin D. Knowledge about sunlight being a very good source of vitamin D was also limited. Though bone and skeletal disorders were identified as a complication of vitamin D deficiency, a large number of subjects were unaware of the other consequences like diabetes, hypertension, obesity, IHD and cancer.

\section{CONCLUSION}

The majority of the study population was unaware of vitamin D, its sources, prevention and complications of its deficiency. Hence, it is recommended that well-designed awareness programmes are needed to eradicate this easily preventable deficiency disorder.

\section{KEYWORDS}

Vitamin D, Awareness, Deficiency, Complications.

HOW TO CITE THIS ARTICLE: Maini S, Arora R, Kaur H. Awareness about vitamin D deficiency and its relation with different disorders. J. Evolution Med. Dent. Sci. 2018;7(14):1749-1752, DOI: 10.14260/jemds/2018/394

\section{BACKGROUND}

Vitamin D deficiency is considered to be the commonest of all the nutritional deficiencies. It is a global problem, which is prevalent in all the age groups with a prevalence of $30 \%$ to $80 \%$ in children and adults.(1) This significantly lowered levels of Vitamin D worldwide in different age groups indicates lack of awareness about the importance of Vitamin $D$, its health benefits and prevention of deficiency states across populations. $(2,3,4)$

Vitamin D deficiency is linked with bone health due to its role in regulation of calcium and phosphate metabolism. In case of vitamin D deficiency, there is ineffective absorption of calcium from the intestine leading to mobilisation of calcium from the bones. This leads to the muscle weakness and an increased risk of fractures in adults and during childhood vitamin D deficiency can cause growth retardation and skeletal deformities. $(5,6)$ In early infancy, it is associated with increased risk of rickets and hypocalcaemic fits. $(7,8)$

Recent studies indicate that vitamin D deficiency is also related with other major diseases such as coronary heart diseases, ${ }^{(9)}$ COPD,(10) type 1 diabetes,(11) obesity(12) and different types of cancers. ${ }^{13,14)}$

'Financial or Other Competing Interest': None.

Submission 19-02-2018, Peer Review 17-03-2018,

Acceptance 22-03-2018, Published 02-04-2018.

Corresponding Author:

Dr. Rajiv Arora

Professor and HOD, Department of Physiology,

Punjab Institute of Medical Sciences,

Jalandhar, Punjab.

E-mail: drrajivarora@yahoo.com

DOI: $10.14260 /$ jemds $/ 2018 / 394$
Production of vitamin D in human body greatly depends on exposure to sunlight. Actually, very few foods naturally contain vitamin $\mathrm{D}$ and as long as there is sufficient exposure to sunlight on a regular basis there is hardly any requirement of vitamin D from any other source. But India even being a sunshine country, vitamin D deficiency is very prevalent in India.(15) The Indians suffer from vitamin D deficiency because most of the students, professionals, housewives and elderly people remain indoors during most of the day.(16) Dark skinned individuals and people who cover most of their skin due to cultural or religious reasons are also at an increased risk of developing this nutritional deficiency. (17)

Vitamin D deficiency is a preventable disorder and the burden of this disorder can be reduced by taking various protective and preventive measures. It has been suggested that awareness and educational campaigns about vitamin D at the community level, targeting both general and high risk populations could help prevent long-term health consequences.(18)

Before initiating educational programs, it is necessary to assess the knowledge and awareness regarding vitamin D amongst the general population groups.

\footnotetext{
Aims and Objectives

This study aims to evaluate the awareness about vitamin D deficiency and its relation with different disorders amongst the general population. It is very important to assess the awareness of general population regarding this preventable disorder, so that effective educational programmes can be designed to increase the level of awareness of the people, thereby improving overall health and general wellbeing.
} 


\section{MATERIALS AND METHODS}

This study was conducted in Punjab Institute of Medical Sciences, Jalandhar. The study was approved by the Institutional Ethical Committee. This research was conducted as a cross-sectional, voluntary survey over a period of one and a half year. The subjects were selected from the Attendants of the patients coming to the OPD or admitted in Punjab Institute of Medical Sciences, Jalandhar. The questionnaire was distributed to 1031 otherwise healthy individuals. Before filling the questionnaire, necessary information was given to the participants. First part of the questionnaire included questions on demographic profile and second part focussed on knowledge about vitamin D.

The questionnaire took approximately 15 minutes to complete. The survey questions assessed the level of knowledge. The participants had with regard to sources of vitamin D what it does for health, factors that affect vitamin D levels and complications of Vitamin D deficiency. Percentage method was used to analyse the data.

\section{RESULTS}

There were 639 females and 392 males amongst the participants. Majority of the subjects were $(41 \%)$ in the age group of 21 to 30 years, $14 \%$ of the subjects were in the age group of 31 to 40 years, $20 \%$ in the age group of 41 to 50 and rest $25 \%$ were in the age group of 51 to 60 years. Most of the subjects were from urban areas (60\%).

\begin{tabular}{|l|c|}
\hline \multicolumn{2}{|c|}{ Table 1. Gender Distribution } \\
\hline Gender & Number (Percentage) \\
\hline Male & $392(38)$ \\
\hline Female & $639(62)$ \\
\hline Total & $\mathbf{1 0 3 1 ( 1 0 0 )}$ \\
\hline
\end{tabular}

\begin{tabular}{|l|l|}
\hline \multicolumn{2}{|c|}{ Table 2. Age Groups of Subjects } \\
\hline Age Groups & Number (Percentage) \\
\hline 21-30 years & $423(41)$ \\
\hline $31-40$ years & $144(14)$ \\
\hline $41-50$ years & $206(20)$ \\
\hline Above 51 & $258(25)$ \\
\hline Total & $\mathbf{1 0 3 1 ( 1 0 0 )}$ \\
\hline
\end{tabular}

\section{Educational Status}

About $33 \%$ of the participants were educated till $10^{\text {th }}$ standard or less, $27 \%$ had completed $12^{\text {th }}$ standard and about $40 \%$ participants were graduates or more.

\begin{tabular}{|l|l|}
\hline \multicolumn{2}{|c|}{ Table 3. Educational Status } \\
\hline Qualification & Number (Percentage) \\
\hline $10^{\text {th }}$ Standard and Less & $340(33)$ \\
\hline $12^{\text {th }}$ Standard & $278(27)$ \\
\hline Graduation or More & $413(40)$ \\
\hline Total & $\mathbf{1 0 3 1 ( 1 0 0 )}$ \\
\hline
\end{tabular}

\section{Knowledge about Vitamin D}

$18 \%$ of the subjects had never heard about Vitamin D. Rest $82 \%$ had heard about vitamin D and knew that vitamin D was important for health.

\section{Diet}

Only $16 \%$ of the subjects were aware that foods such as milk, milk products, eggs and fish are rich source of vitamin $\mathrm{D}$, rest $84 \%$ of the study population did not know about the dietary sources of vitamin D.

\section{Exposure to the Sun}

About 78\% participants knew that exposure to sunlight was an important source of vitamin D, but only $40 \%$ of the total participants had the knowledge about the duration of exposure to sunlight required for production of vitamin D in the body.

\section{Symptoms}

About $72 \%$ of the participants were aware that Vitamin D deficiency is associated with bones and muscle pain and $28 \%$ of the participants were not aware of the symptoms of the Vitamin D deficiency. A significant percentage (91\%) of the participants did not know when they should get their vitamin D levels investigated.

\section{Supplements}

Only $11 \%$ of the subjects reported that they were taking vitamin D supplements and rest $89 \%$ were not taking vitamin D supplements.

\section{Complications}

About $54 \%$ of the participants identified arthritis as the only long-term complication of vitamin D deficiency. Another $5 \%$ identified hypertension as one of the possible outcomes of vitamin D deficiency. About 4\% knew that ischaemic heart disease can be one of the serious complications of longstanding vitamin D deficiency. Only $2 \%$ related vitamin D deficiency as one of the factors causing diabetes. Rest 35\% participants did not know anything about possible complications of vitamin D deficiency.

\section{At Risk Status}

Almost 29\% participants did not have knowledge about the people, which are at greater risk of developing vitamin D deficiency. Rest $71 \%$ knew that people who remain indoors due to various reasons are at greater risk of developing this deficiency.

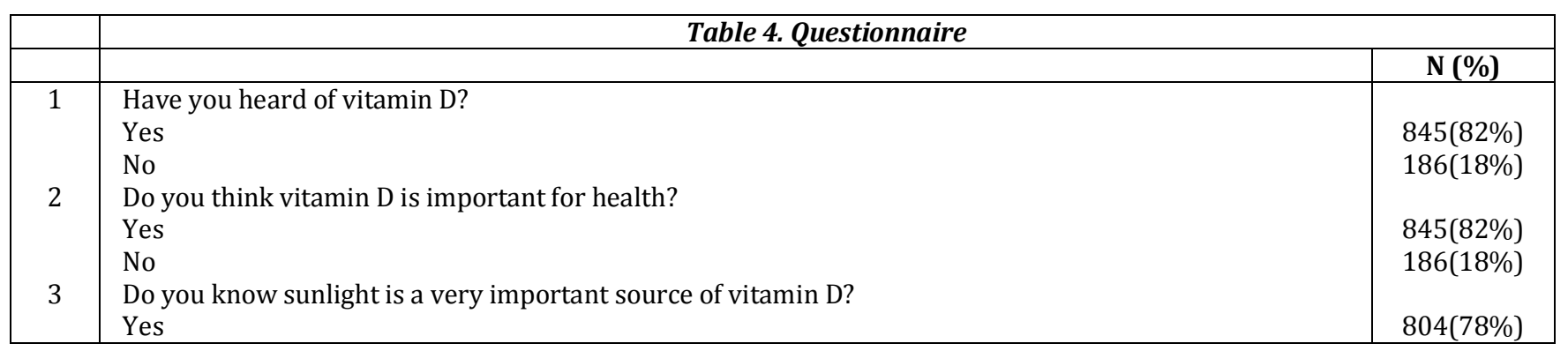




\begin{tabular}{|c|c|c|}
\hline \multirow{3}{*}{4} & No & $227(22 \%)$ \\
\hline & $\begin{array}{l}\text { Do you know how much sun exposure is needed to get adequate } \\
\text { Vitamin D? }\end{array}$ & \\
\hline & Yes & $412(40 \%)$ \\
\hline \multirow[t]{2}{*}{5} & No & $619(60 \%)$ \\
\hline & $\begin{array}{l}\text { Do you know foods such as milk, milk products, eggs and fish are rich sources of vitamin D? } \\
\text { Yes }\end{array}$ & $165(16 \%)$ \\
\hline 6 & $\begin{array}{l}\text { No } \\
\text { Do you know that vitamin D deficiency causes bones and muscle pain, tiredness } \\
\text { and low mood? }\end{array}$ & $866(84 \%)$ \\
\hline \multirow[t]{3}{*}{7} & Yes & $742(72 \%)$ \\
\hline & No & $289(28 \%)$ \\
\hline & Do you when you should get your vitamin D levels investigated? & \\
\hline \multirow[t]{3}{*}{8} & Yes & $93(9 \%)$ \\
\hline & No & 938(91\%) \\
\hline & Do you take vitamin D supplements (tablets)? & \\
\hline \multirow[t]{6}{*}{9} & Yes & $113(11 \%)$ \\
\hline & No & $918(89 \%)$ \\
\hline & What are the long-term complications of vitamin D deficiency & \\
\hline & Arthritis & $556(54 \%)$ \\
\hline & Hypertension & $52(5 \%)$ \\
\hline & Ischaemic heart disease & $41(4 \%)$ \\
\hline \multirow[t]{5}{*}{10} & Diabetes & $21(2 \%)$ \\
\hline & Do not know & $361(35 \%)$ \\
\hline & Do you know that the people who remain indoors are at a greater risk of developing vitamin D deficiency? & \\
\hline & Yes & $732(71 \%)$ \\
\hline & No & $299(29 \%)$ \\
\hline
\end{tabular}

\section{DISCUSSION}

This study revealed that majority of the study population is not aware of the sources, symptoms and complications of vitamin D deficiency. Majority of the study population included foods rich in their diet, but their knowledge about sources of vitamin D is limited. Most of the participants identified bone and muscle pain as the symptom of vitamin deficiency. Most of the participants recognised arthritis as the only complication of untreated vitamin D deficiency. Most of them did not know that vitamin D deficiency is also associated with disorders like diabetes, hypertension, ischaemic heart disease, stroke and cancer.

Results of this study are consistent with those conducted in other regions of India and other countries when it comes to identifying lack of awareness about vitamin D deficiency. In study conducted by Christie (2011) in Saudi Arabia, it was found that people had limited knowledge about vitamin D and vitamin D deficiency.(19) They reported limited sun exposure due to intense heat, cultural reasons for covering their body and an infrastructure that made sun exposure difficult. In another study conducted by Farida M Habib et al in Riyadh (2014), it was found that knowledge of the participants to prevent vitamin D deficiency was insufficient.(20) In a study conducted by Yangshen Lhemo et al in New Delhi, it was concluded that there was a lack of knowledge about the importance of vitamin D, worldwide prevalence of vitamin D deficiency and its management among the medical students.(21) In another study conducted at AIIMS, Rishikesh by Vasantha Kalyani and Shaina Sharma,(22) it was found that there was lack of awareness about vitamin D deficiency amongst the study population.

\section{CONCLUSION}

This study highlighted lack of awareness about vitamin D deficiency among the study population. Majority of the participants did not know that exposure to the sunlight was very important to prevent this deficiency. Most of the study population was not aware about the sources of vitamin $\mathrm{D}$, symptoms of vitamin D deficiency and its relation with disorders like ischaemic heart disease, diabetes, hypertension, obesity, multiple sclerosis and cancer. This knowledge deficit calls for the need to organise the awareness programs to educate people about vitamin D deficiency and its serious outcomes. Effective educational programmes to increase public awareness about vitamin D and its sources are required to improve overall health and wellbeing of the people of this region.

\section{REFERENCES}

[1] Al-Agha AE, Alorabi SH, NoorSaeed SMW, et al. Awareness of vitamin D and its deficiency in Jeddah population, Saudi Arabia. Journal of Community and Public Health Nursing 2016;2:120.

[2] Mithal A, Wahl DA, Bonjour JP, et al. Global vitamin D status and determinants of hypovitaminosis D. Osteoporosis International 2009;20(11):1807-20.

[3] Pettifor JM. Vitamin D and/or calcium deficiency rickets in infants and children: a global perspective. Indian Journal of Medical Research 2008;127(3):2459.

[4] Hagenau T, Vest R, Gissel TN, et al. Global vitamin D levels in relation to age, gender, skin pigmentation and latitude: an ecologic meta-regression analysis. Osteoporosis International 2009;20(1):133-40.

[5] Pettifor JM. Vitamin D deficiency and nutritional rickets in children in vitamin D. In: Feldman D, Pike JW, Glorieux FH, eds. Vitamin D. 2nd edn. Boston, Mass, USA: Elsevier Academic Press 2005: p. 1065-84. 
[6] Marwaha RK, Tandon N, Reddy DR. Vitamin D and bone mineral density status of healthy school children in northern India. American Journal of Clinical Nutrition 2005;82(2):477-82.

[7] Ahmed I, Atiq M, Iqbal J, et al. Vitamin D deficiency rickets in breast fed infants presenting with hypocalcaemic seizures. Acta Peadiatrica 1995;84(8)941-2.

[8] Camadoo I, Tibbott R, Isaza F. Maternal vitamin D deficiency associated with neonatal hypocalcaemic convulsions. Nutr J 2007;6:23.

[9] Dhibar DP, Sharma YP, Bhadada SK, et al. Association of vitamin D deficiency with coronary artery disease. Journal of Clinical and Diagnostic Research 2016;10(9):OC24-0C8.

[10] Sanket S, Madireddi J, Stanley W, et al. Relation between vitamin D deficiency and severity of chronic pulmonary obstructive disease - a case control study. Journal of Clinical and Diagnostic Research 2016;10(1):OC16-OC19.

[11] Alshamsan F, Elgabry E, Bin-Abbas B. Vitamin D deficiency is comparatively more prevalent in female children with type 1 diabetes in a high Vitamin D deficiency risk country. Middle East Journal of Family Medicine 2014;7:31.

[12] De Souza SJ, Pereira SE, Sobrinho CJS, et al. Obesity, related diseases and their relationship with vitamin $D$ deficiency in adolescents. Nutr Hosp 2016;33(4):85664.

[13] Garland CF, Garland FC, Gorham ED, et al. The role of vitamin D in cancer prevention. Am J Public Health 2006;96(2):252-61.
[14] Holick MF. Sunlight and vitamin D for bone health and prevention of autoimmune diseases, cancers and cardiovascular diseases. Am J Clin Nutr 2004;80(Suppl 6):S1678-S88.

[15] Khadilkar AV. Vitamin D deficiency in Indian adolescents. Indian Peadiatr 2010;47(9):755-6.

[16] D'Souza P. Why most Indians are vitamin D deficient. Hindustan Times, Mumbai/ updated Apr 05, 2013;17:58 IST.

[17] Al Bathi BA, Al Zayed KE, Qenai Al et al, Knowledge, attitude and practice of patients attending primary care centres towards vitamin D in Kuwait. Alexandria J of Med 2012;48(3):277-82.

[18] Von Bothmer MI, Fridlund B. Gender differences in health habits and in motivation for a healthy lifestyle among Swedish university students. Nursing and Health Sciences 2005;7(2):107-18.

[19] Christie FT, Mason L. Knowledge, attitude and practice regarding vitamin D deficiency among female students in Saudi Arabia: a qualitative exploration. International Journal of Rheumatic Diseases 2011;14(3):e22-9.

[20] Habib FM, Al-Motairi WA, Al-Mutairi WA. Vitamin D deficiency: knowledge and practice among adult Saudi females. Global Advanced Research Journal of Medicine and Medical Science 2014;3(5):095-101.

[21] Lhamo Y, Chugh PK, Gautam SR, et al. Epidemic of vitamin $\mathrm{D}$ deficiency and its management: awareness among Indian medical undergraduates. Article ID 2517207, Journal of Environmental Health 2017;2017: p. 7.

[22] Kalyani V, Sharma S. Awareness of vitamin D deficiency among females attending the OPD, AIIMS, Rishikesh. Journal of Nursing and Health Sciences 2016;5(4):76-8. 